\title{
Nutrition, physical activity and health status in Middle and East European countries
}

\author{
H.-J. Franz Zunft ${ }^{1 *}$, Gotfried Ulbricht ${ }^{1}$, Jan Pokorný ${ }^{2}$, Wlodzimierz Sekula ${ }^{3}$, \\ Lucjan Szponar ${ }^{3}$ and J.-Algis Abaravicius ${ }^{4}$ \\ ${ }^{1}$ German Institute of Human Nutrition, Potsdam-Rehbruecke, Germany ${ }^{2}$ Prague Institute of Chemical Technology, \\ Prague, Czechia ${ }^{3}$ National Food and Nutrition Institute, Warsaw, Poland ${ }^{4}$ Vilnius University, Faculty of Medicine, \\ Vilnius, Lithuania
}

Accepted: 22 June 1999

\begin{abstract}
In the Middle- and East-European countries the political, economic and social situation changed fundamentally in 1989 and 1990. These alterations are reflected in markers of dietary intake, physical activity and health with a trend similar in Czechia, East Germany, Lithuania and Poland. Thus, the previous increase in energy consumption stopped and was followed by a decline. The increasing preference for a lower level of activity is demonstrated by the number of private cars clearly accelerating its rate of growth after the change. Life expectancy had been increasing during the eighties only slightly. After the change the yearly increase became higher than before. The rate difference is higher in men than in women. Beginning from 1991 the CVD mortality decreased considerably.
\end{abstract}

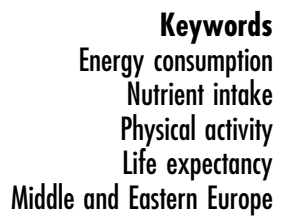

Keywords

Nutrient intake

Physical activity

Middle and Eastern Europe

\section{Introduction}

Nutrition and physical activity interact in their influence on health. The epidemic rise in obesity and other diseases of the metabolic syndrome in affluent societies are largely caused by energetic overnutrition, esp. overconsumption of dietary fat, and a continuous fall in occupational physical activity without compensation by leisure-time exercise ${ }^{1,2}$. Health, however, is also influenced by economic, social, and cultural conditions in a society. Thus, the interaction between diet, physical activity and health may reflect changes in the political and economic system of a country ${ }^{3,4}$.

In Europe such alterations being the most radical ones during the last 50 years happened in all countries which belonged to the former Warsaw treaty. These Middle- and East-European countries underwent a process of democratization shifting the political system, sweeping away the socialist economy and mixing up the rooted social relations.

This short communication demonstrates for selected countries (Czechia, East-Germany (the former GDR), Lithuania, Poland) whether and to what extent these events are reflected in alterations of dietary intake, physical activity and health.

This information cannot be derived from a unique and representative data base. Moreover, data from different countries differ in their quality and are comparable to each other only to a certain degree. Thus, a lot of data sources, mainly the official statistics published yearly in every country had to be used. Exceptionally, for specific questions single scientific studies were evaluated.

\section{Dietary intake}

Dietary intake can be approximately calculated using the agricultural statistics on food consumption published by the agricultural ministries of each country.

In Czechia, Germany and Poland energy consumption increased continuously during the eighties (Fig. 1). This trend was interrupted with the political change around 1990. Thereafter the energy intake decreased slightly. This drop finished in 1994 and 1995 and energy consumption started to rise again. This time course is quite similar in Czechia and Poland. For East Germany, however, no regional data exist after reunification. Therefore, additional information was obtained from household budget surveys (carried out by the Statistisches Bundesamt, Berlin, Germany). For a specific subpopulation (men from families with 2 adults and 2 children and with a medium income) the time course of the energy-consumption/time relation corresponds with that in both the other countries.

The qualitative change in the energy consumption during the last two decades is not reflected in the relative amount of dietary protein, fat and carbohydrates expressed as percent of total energy (Table 1). Minor differences before and after 1989/1990 can be observed, e.g. in Lithuania as an increase in the fat 


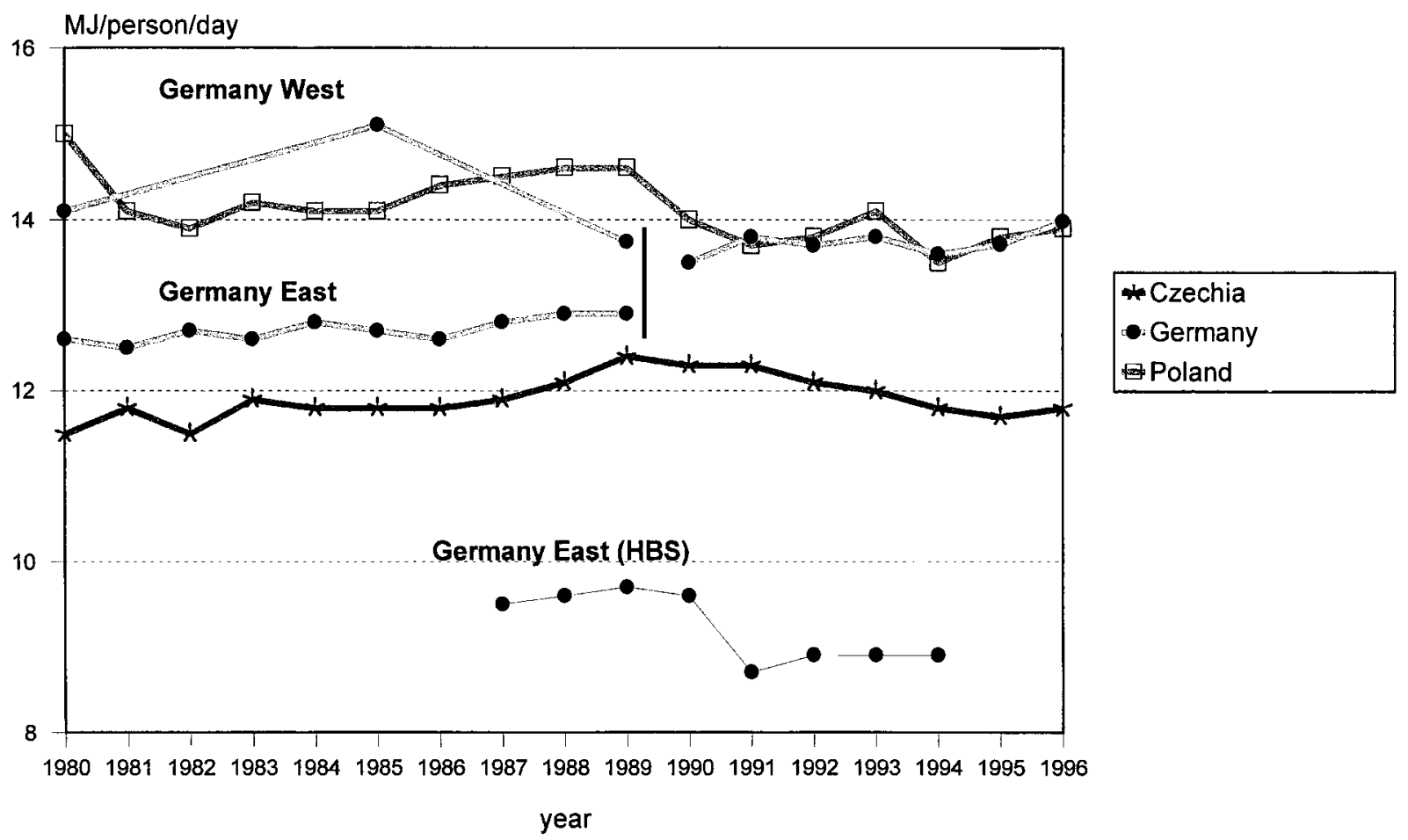

Fig 1 Energy consumption from 1980 to 1996 in Czechia, Germany and Poland, estimated from the official agricultural statistics, and for Germany East additionally energy intake for the indoor consumption of males in a 2 adults/2 children-household, estimated by the Household Budget Statistics (HBS)

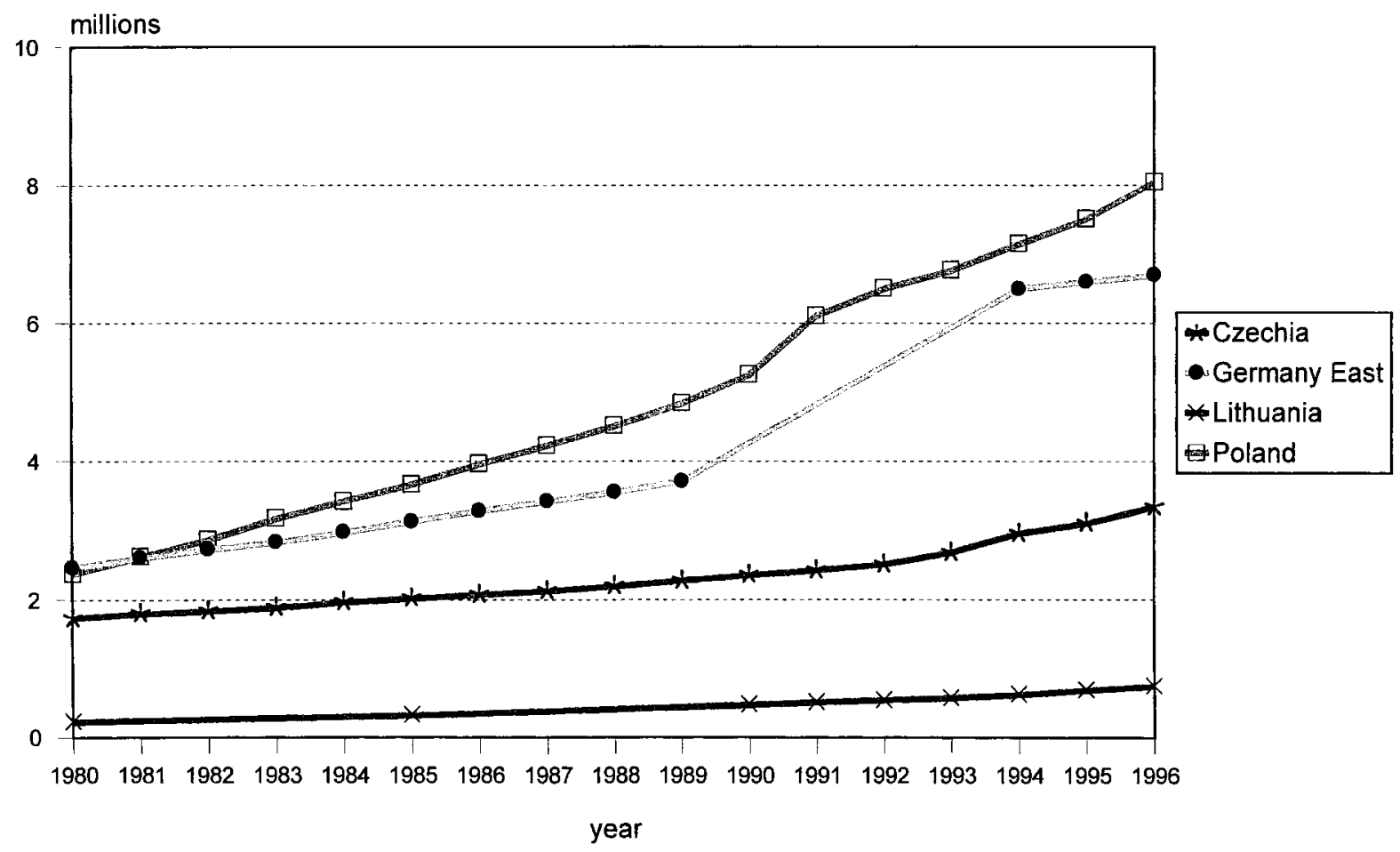

Fig 2 Number of private cars from 1980 to 1996 in Czechia, Germany East, Lithuania and Poland 
and a decrease in the carbohydrate portion. However, those changes do not occur in the countries in a similar way and, thus, cannot be related to the political events.

The changes in dietary intake described in this study coincide with results reported by several authors from Czechia, East Germany and Hungary ${ }^{3-5}$.

\section{Physical activity}

The physical activity on population level has continuously decreased during the last decades as documented in the literature ${ }^{6-8}$. This is particularly caused by the reduced occupational activity. Moreover, in leisure time physical exercise diminishes ${ }^{9,10}$. For
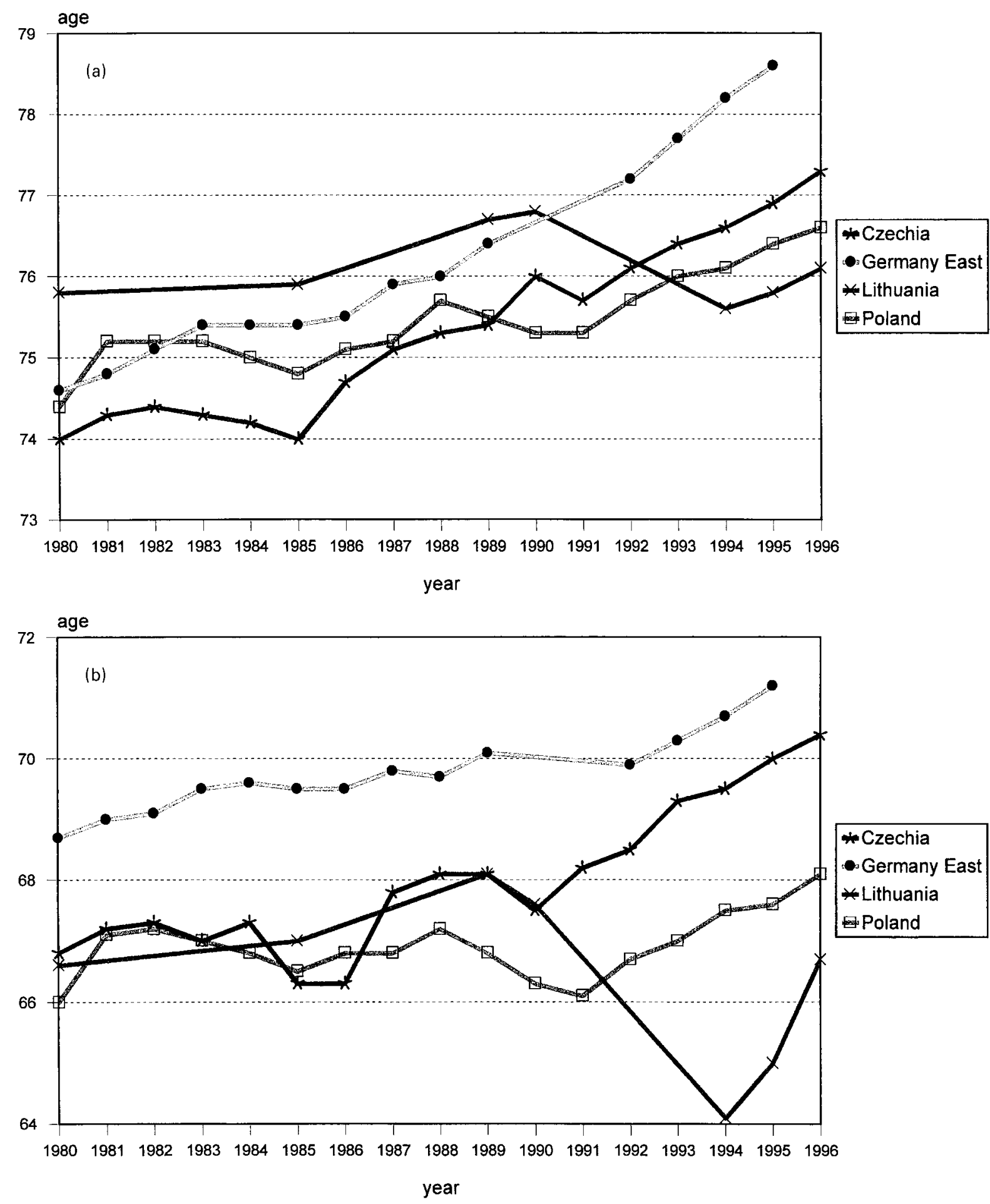

Fig 3 Life expectancy from 1980 to 1996 in Czechia, Germany East, Lithuania and Poland A: Females B: Males 
Table 1 Contribution of dietary protein, fat and carbohydrate to the total energy intake before, during and after the political and economic change in Czechia (CZ), Germany East (D), Lithuania $(\mathrm{LT})$, and Poland (PL)

\begin{tabular}{cccc}
\hline \multicolumn{1}{c}{$1980-1989$} & $1990-1992$ & $1993-1997$ \\
\hline Protein & \multicolumn{3}{c}{ \% of energy intake } \\
CZ & 12.4 & 12.3 & 12.0 \\
D & 12.1 & 12.7 & 12.6 \\
LT & 13.4 & 13.8 & 13.0 \\
PL & 10.6 & 10.7 & 10.1 \\
Fat & & & \\
CZ & 26.9 & 26.1 & 25.6 \\
D & 40.4 & 39.8 & 40.5 \\
LT & 39.1 & 42.3 & 44.0 \\
PL & 32.9 & 33.8 & 33.2 \\
Carbohydrates & & & \\
CZ & 60.7 & 61.6 & 62.4 \\
D & 47.5 & 47.5 & 46.9 \\
LT & 47.5 & 43.9 & 43.0 \\
PL & 56.5 & 55.5 & 56.7 \\
\hline
\end{tabular}

none of the countries Czechia, Germany, Lithuania and Poland there exist any representative and comparable data. Therefore, the number of private cars is used to demonstrate the increasing preference for a lower level of activity (Fig. 2). Although a private car may contribute to a higher individual level of exercise, e.g. by making easier sportive activities on the family level, above all it is used to reduce physical efforts. In all the four countries the number of cars increased continuously during the eighties and the nineties. However, the events of 1989/1990 are reflected by a higher rate of increase, in Poland in 1991, in Czechia with a certain delay in 1994.

\section{Life expectancy and mortality}

Life expectancy is a general and long-term marker of the health situation in a country. Nevertheless, as illustrated in Fig. 3A and 3B the political and economic changes are clearly reflected in the trends of life expectancy in all the four countries. Before that time, life expectancy had been increasing slightly, with a higher rate in females. After 1990, besides a drop in Lithuania, the yearly increase in life expectancy has been higher than before. This rate difference is obvious in women, but much higher in men.

A similar development can be observed in the mortality of cardiovascular diseases (Fig. 4). The CVD mortality in Czechia and Poland for both genders increased in the early eighties and stayed constant from 1985 to 1990. In Germany (East) the CVD mortality fell with a moderate rate during that time. Beginning from 1991 in all the countries the CVD mortality decreased clearly.

\section{Conclusion}

The political, economic and social alterations happening in 1989 and 1990 in the Middle- and East-European countries are clearly reflected in selected markers of

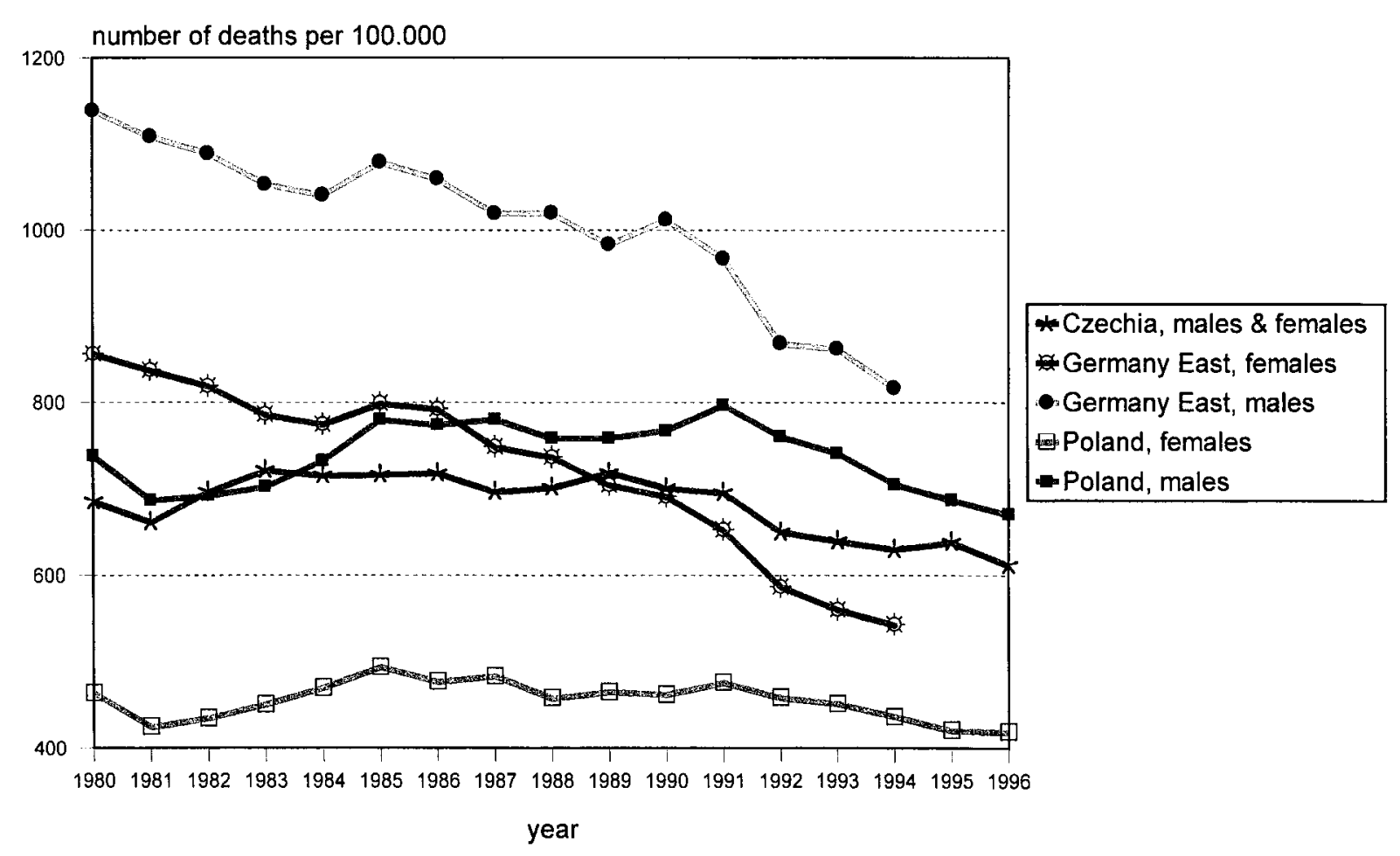

Fig 4 Mortality of cardiovascular diseases (ICD‘9: 390-459) from 1980 to 1996 in Czechia, Germany East and Poland 
dietary intake, physical activity and health. Of course, from the data presented here no causal relationship can be concluded. For direct influences of diet and physical activity on mortality the time-span between exposure and outcome is much too short. However, the data reflect the immense effects economic and social conditions have on life-style factors as nutrition and physical activity and on health.

\section{References}

1 Kuczmarski RJ, Flegal KM, Campbell SM, Johnson CL. Increasing prevalence of overweight among US adults. JAMA 1994; 272: 205-11.

2 Seidell JC. Obesity in Europe: scaling an epidemic. Int. J. Obes. 1995; 19: S1-4.

3 Biro G. Impact of political, social and economic changes on food and nutrition in Central and Eastern European countries. Proceedings of the European Interdisciplinary Meeting "Current Research into Eating Practices. Contributions of
Social Sciences". AGEV Publication Series, Vol. 10, Ernaebrungs-Umschau, Suppl. 1995; 42: 198-200.

4 Hrubý J, Ulbricht G. Change in former communist countries and its impact on nutrition behaviour: examples from two Central European countries. Proceedings of the European Interdisciplinary Meeting Current Research into Eating Practices. Contributions of Social Sciences. AGEV Publication Series, Vol. 10, Ernaehrungs-Umschau, Suppl. 1995; 42: 201-206.

5 Thiel C, Heinemann L, Do Minh Thai. Lebensmittelaufnahme und Naehrstoffversorgung in den neuen und alten Bundeslaendern. Ernaehrungs-Umschau 1993; 40: 486-490.

6 Blair SN, Kohl HW, Gordon NF, Paffenbarger RS. How much physical activity is good for health? Am. Rev. Public Health 1992; 13: 99-126.

7 Johnson NA, Boyle CA, Heller RF. Leisuretime physical activity and health behaviours: are they related? Aust. J. Public Health 1995; 19: 69-75.

8 Mensink GBM, Deketh M, Mul MDM, Schuit AJ, Hoffmeister H. Physical activity and its association with cardiovascular risk factors and mortality. Epidemiology 1996; 7: 391-7.

9 Hoffmeister H, Bellach B. Die Gesundheit der Deutschen. RKI-Heft 1995; 7.

10 Bellach BM. Die Gesundheit der Deutschen. RKI-Heft 1996; 15. 